\title{
EBV-positive diffuse large B-cell lymphoma in a patient with primary Sjögren's syndrome and membranous glomerulonephritis
}

\author{
Chang Seong Kim ${ }^{1}$, Yoo Duk Choi ${ }^{2}$, Joon Seok Choi ${ }^{1}$, Eun Hui Bae ${ }^{1}$, Seong Kwon Ma ${ }^{1}$ and Soo Wan Kim ${ }^{1 *}$
}

\begin{abstract}
Background: Sjögren's syndrome is a systemic autoimmune disease in which lymphatic cells destroy the salivary and lacrimal glands. Glomerulonephritis is thought to be a rare occurrence in primary Sjögren's syndrome. Furthermore, concurrent glomerular involvement and lymphoma in patients with Sjögren's syndrome has seldom been reported.

Case presentation: A 52-year-old woman with primary Sjögren's syndrome developed membranous glomerulonephritis and Epstein-Barr virus-positive diffuse large B-cell lymphoma (DLBCL). She was diagnosed with Sjögren's syndrome based on the dry eyes, dry mouth, positive anti-nuclear antibody test, anti-Ro (SS-A) antibody, salivary gland biopsy, and salivary scintigraphy. Moreover, renal biopsy confirmed the diagnosis of membranous glomerulonephritis. Three months later, her small bowel was perforated with pneumoperitoneum, and the biopsy revealed Epstein-Barr virus-positive DLBCL.

Conclusions: We observed the first case of primary Sjögren's syndrome associated with Epstein-Barr Virus-positive DLBCL and membranous glomerulonephritis. Because of the possibility of malignancy-associated membranous glomerulonephritis in patients with primary Sjögren's syndrome, we should be careful and examine such patients for hidden malignancy.
\end{abstract}

Keywords: Primary Sjögren's syndrome, Membranous glomerulonephritis, EBV-positive diffuse large B-cell lymphoma

\section{Background}

Sjögren's syndrome is an autoimmune disease characterized by lymphocytic infiltration of salivary and lacrimal glands, typically presenting with keratoconjunctivitis and xerostomia [1]. Extraglandular manifestations of Sjögren's syndrome occur in up to a third of patients [2]. Patients with Sjögren's syndrome can have accompanying interstitial lung disease [3], cutaneous vasculitis [4], peripheral neuropathy [5], hematologic complications [6], and renal involvement. Tubulointerstitial nephritis is the most common renal manifestation of primary Sjögren's syndrome; whereas, glomerulonephritis is rare in comparison [7]. On the other hand, the most feared complication of primary Sjögren's syndrome is lymphoproliferative

\footnotetext{
* Correspondence: skimw@chonnam.ac.kr

${ }^{1}$ Department of Internal Medicine, Chonnam National University Medical

School, 42 Jebongro, Gwangju 501-757, South Korea

Full list of author information is available at the end of the article
}

malignancy. The risk of malignant non-Hodgkin's lymphoma (NHL) is increased in primary Sjögren's syndrome [6]. Moreover, Epstein-Barr virus (EBV)-positive diffuse large B-cell lymphoma (DLBCL) is rarer and is associated with poorer overall survival than EBV-negative DLBCL. In addition, intestinal involvement and perforation is very rare. Here, we report the case of a 52-year-old woman diagnosed with primary Sjögren's syndrome associated with EBV-positive DLBCL and membranous glomerulonephritis.

\section{Case presentation}

A 52-year-old woman was admitted to hospital for evaluation of intermittent abdominal tenderness, dry eye, and dry mouth. The dry eye and dry mouth had been present for several years; however, she had not sought medical treatment for these symptoms. She had a history of dilated cardiomyopathy and glaucoma of the left eye. 
She was being treated with loop diuretics, proton pump inhibitors, and anthocyanosides for glaucoma. In the physical examination, her lower extremities were in an edematous state. Her body temperature was $36.5^{\circ} \mathrm{C}$ and blood pressure was normal. The results of the laboratory studies were as follows: white blood cell count, 8,600/ $\mathrm{mm}^{3}$ (neutrophil 73.4\%); sodium, $141 \mathrm{mEq} / \mathrm{L}$; chloride, $108 \mathrm{mEq} / \mathrm{L}$; blood urea nitrogen, $15.7 \mathrm{mg} / \mathrm{dL}$; and creatinine, $0.6 \mathrm{mg} / \mathrm{dL}$. The levels of total serum protein, serum albumin, and total cholesterol were $5.5 \mathrm{~g} / \mathrm{dL}, 1.5$ $\mathrm{g} / \mathrm{dL}$, and $257 \mathrm{mg} / \mathrm{dL}$, respectively. Urinalysis was remarkable for proteinuria (6.3 g/day), 30-49 red blood cells per high-power field, but no other casts. Serologic investigation revealed the presence of anti-nuclear antibody (ANA; 1:80, homogeneous plus speckled pattern), rheumatoid factor $(390 \mathrm{IU} / \mathrm{mL})$, and was positive for autoantibody to the Ro (SS-A) antigen (>200 U/mL). However, serology was negative for antibodies against double-stranded DNA, La (SS-B), Sm, ribonucleoproteins, antineutrophil cytoplasmic antibodies, lupus anticoagulant, IgG/IgM anti-cardiolipin, and IgG $\beta 2$-glycoprotein-1. The C3 levels had decreased to $38 \mathrm{mg} / \mathrm{dL}$ (normal, 90-180 $\mathrm{mg} / \mathrm{dL}$ ), whereas $\mathrm{C} 4$ and total hemolytic complement 50 levels were within normal ranges at $16 \mathrm{mg} / \mathrm{dL}$ and 33.1 $\mathrm{U} / \mathrm{mL}$, respectively (normal ranges, $10-40$ and 23-46, respectively). Tests for hepatitis B surface antigen, hepatitis $\mathrm{C}$ antibodies, cryoglobulins, and human immunodeficiency virus antibodies were negative.

Minor salivary gland biopsy was performed, showing diffuse lymphocytic infiltrations with a focus score of 3 [8]. Moreover, we performed salivary scintigraphy that showed non-visualization in both salivary glands, consistent with the class 4 Schall grading system [9]. Therefore, she was diagnosed with Sjögren's syndrome based on the dry eyes, dry mouth, positive ANA, anti-Ro (SS-A) antibody, salivary gland biopsy, and salivary scintigraphy, which fulfilled the 2002 American-European consensus classification criteria [10].

She underwent a percutaneous renal biopsy due to nephrotic syndrome. Glomerular basement membrane thickening and mesangial matrix widening were observed by light microscopy (Figure 1A). In addition, mild tubular atrophy and moderate interstitial fibrosis was noted. Weakly positive staining for IgG, IgA, IgM, and C3 on the outer surface of capillary walls was revealed by immunofluorescent staining. Diffuse subepithelial electron-dense deposit was observed by electron microscopy (Figure 1B). The histopathological findings were consistent with membranous glomerulonephritis [11].

Abdominal computed tomography (CT) and colonoscopy were performed due to intermittent abdominal tenderness; however, we did not observe any malignancy or bowel perforation at admission except for enteritis and multiple small lymphadenopathies in the mesentery. She had sudden onset of severe abdominal pain 3 months later, and abdominal CT was performed again. Newly developed pneumoperitoneum with peritonitis accompanied by small bowel perforation was observed. An emergency operation and small bowel biopsy were performed. The specimen was $9.5 \mathrm{~cm}$ in axial length and had a necrotic and ulcerous $(4.5 \times 5 \mathrm{~cm})$ lesion. On immunohistochemical examination, we found expression of CD20, CD79a, and BCL-2, but not of CD3, CD10, and BCL-6. The proliferation fraction as determined by $\mathrm{Ki}-67$ was $50 \%-60 \%$. The majority of tumor cells were positive for EBV by in situ hybridization. Biopsy revealed EBV-positive DLBCL (Ann Harbor classification stage III), as demonstrated in Figure 2. The patient declined treatment with chemotherapy because of poor performance status, low compliance, and poverty. However, she had been receiving intermittent low-dose oral corticosteroid and hydroxychloroquine to treat her primary Sjögren's syndrome since the diagnosis. There was improvement in proteinuria (1.79 g/day) and sicca symptoms after 1 year of follow-up. One year of follow-up positron emission tomography-CT scan showed a stable disease state for the malignant lymphoma.

\section{Conclusions}

Lymphoma is more common in patients with autoimmune disease, especially those with primary Sjögren's

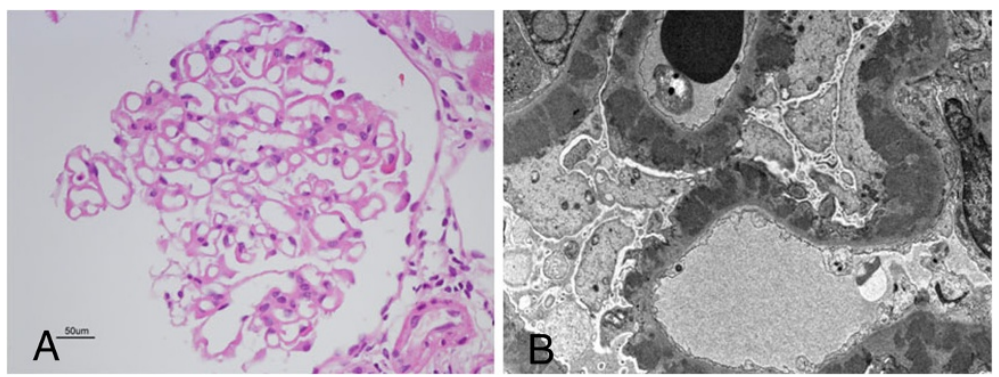

Figure 1 Percutaneous renal biopsy. (A) On light microscopy, glomeruli show a diffuse thickening of basement membrane with normocellularity (Magnification: x400). (B) On electron microscopy, diffuse subepithelial electron dense deposits are easily identified. (Magnification: x2500). 


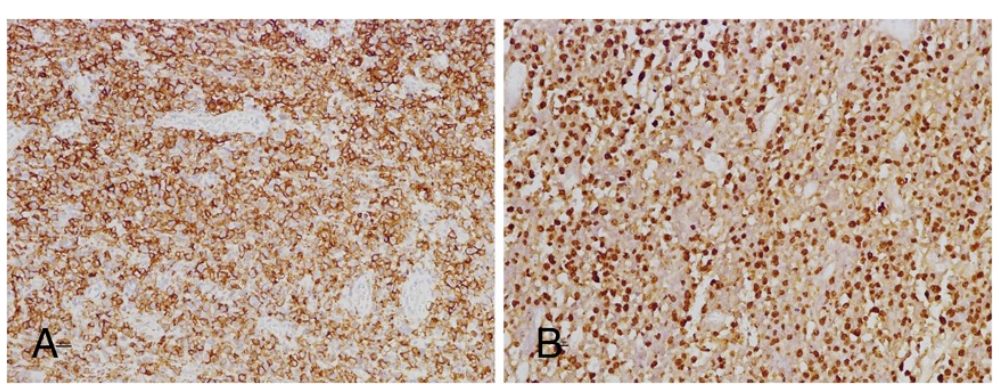

Figure 2 Small bowel biopsy. (A) The tumor cells have immunoreactivity for CD20. (Magnification: x100). (B) The tumor cells have a positive reaction for EBV in situ hybridization. (Magnification: $\times 100$ ).

syndrome [6]. The relative risk of lymphomas in primary Sjögren's syndrome was found to be 16-44 times higher than in the general population in 2 large case series studies [12,13]. Patients with primary Sjögren's syndrome have risk factors for progression to lymphoma, such as persistent enlarged parotid glands, splenomegaly, lympadenopathy, palpable purpura, leg ulcers, peripheral nerve involvement, anemia, neutropenia, low-grade fever, low levels of C3 and C4, and mixed cryoglobulinemia [13]. In this case, risk factors for malignant lymphoma included low levels of C3, anemia, and multiple small lymphadenopathies detected by abdominal CT.

EBV-positive DLBCL is characterized by EBV-positive clonal B cell lymphoproliferation that occurs in patients aged over 50 years without any immunodeficiency or prior lymphoma. It is a recently defined subgroup of DLBCL in the 2008 World Health Organization classification of lymphoid neoplasm [14]. The pathogenetic role of the EBV in NHL is circumstantial; however, EBV is able to drive cellular proliferation as a potential carcinogen [15]. In this case, we speculated that this virus assisted in the progression of the malignant lymphoma. Patients with age-related EBV-positive DLBCL are older, have more aggressive clinical features, are rarer (9\%) [16], and have poorer overall survival, as compared with EBV-negative DLBCL patients. Lymphoma complicated with Sjögren's syndrome is usually localized in extranodal areas such as salivary glands, the gastrointestinal tract, the thyroid gland, lung, kidney, or orbit [17]; however, common sites of extranodal involvement in EBVpositive DLBCL are skin, lung, pleural effusion, stomach, and tonsil [18]. Concurrent primary small-bowel involvement and perforation is a very rare clinical manifestation in patients with EBV-positive DLBCL [19], especially in those with accompanying Sjögren's syndrome.

Interestingly in our case, it is possible that secondary membranous glomerulonephritis was related to primary Sjögren's syndrome or malignant lymphoma. Clinically significant renal disease is rare in primary Sjögren's syndrome, but latent involvement is relatively common. Renal abnormalities have been reported at varying rates, from $3 \%$ to $67 \%$, in patients with primary Sjögren's syndrome, according to different studies [20-24]. Nevertheless, Kaufman et al. [2] analyzed 180 case reports of renal involvement in primary Sjögren's syndrome in a review of the literature; in 89 cases, patients underwent renal biopsies that revealed interstitial nephritis in 49 cases (55\%), glomerulonephritis in 33 cases (37\%), and both interstitial nephritis and glomerulonephritis in 7 cases (8\%). However, renal biopsies been performed in only half of the reported cases; therefore, the true prevalence of membranous glomerulonephritis remains unknown. There have been only 3 previous cases reported of membranous glomerulonephritis and primary Sjögren's syndrome, to our knowledge [7,25]. From a different point of view, patients with NHL manifest a great variety of glomerular lesions, and several case reports on glomerulonephritis associated with NHL have been published [26-30]. In addition, even if membranoproliferative glomerulonephritis was more common, membranous glomerulonephritis has been reported in 5 of 47 cases (approximately 10\%) among glomerulopathies associated with NHL, in a study by Ronco et al. [31]. Furthermore, the onset of proteinuria occurs with the development of lymphoma, or may slightly precede the clinical detection of lymphoma by several months. There have been several case reports where nephritic syndrome was detected prior to the diagnosis of NHL [32-36]. In our case, the patient presented with nephritic syndrome more than 3 months prior to the diagnosis of NHL. In this context, we can tentatively propose the possibility that the secondary membranous glomerulonephritis was related to DLBCL in this case.

Serological abnormalities including those of rheumatoid factor, cryoglobulins, ANA, anti-Ro, and anti-La are common in secondary glomerulonephritis with Sjögren's syndrome; however, serum complement levels are generally normal unless the patient has associated systemic lupus erythematosus. Goules et al. reported the immunological profile of 10 patients with glomerulonephritis in Sjögren's syndrome; 2 patients demonstrated low levels of C3, 5 patients had decreased C4 serum levels, 
and there was 1 patient who had low $\mathrm{C} 3$ and normal C4 serum levels. These findings are consistent with those of our case, in which the patient had low C3 and normal $\mathrm{C} 4$ levels. The underlying mechanisms are still not completely understood, however, there are varying forms of complement abnormalities in renal involvement accompanying Sjögern's syndrome. Therefore, further study is needed to better understand complement abnormalities.

Although only a few case reports have described treatment with corticosteroid alone or in combination with cyclophosphamide in primary Sjögren's syndrome with renal disease, such treatment has generally led to good clinical outcomes [2]. In 1 case report [36], Sjögren's syndrome complicated with membranous glomerulonephritis resulting from malignant lymphoma resolved after treatment with CHOP (cyclophosphamide, doxorubicin, vincristine, and predinisolone) and radiation. Nevertheless, our patient could not be treated with immunosuppressive therapy or chemotherapy because of her poor general condition. We anticipate that an adequate treatment would be helpful for improvement of the disease.

In conclusion, to the best of our knowledge, we report the first case of primary Sjögren's syndrome associated with EBV-positive DLBCL and membranous glomerulonephritis. If patients with primary Sjögren's syndrome show concurrent membranous glomerulonephritis, they should be carefully examined for hidden malignancy, including EBV-positive DLBCL, because of the possibility of malignancy-associated membranous glomerulonephritis.

\section{Consent}

Written informed consent was obtained from the patient for publication of this case report and any accompanying images.

\section{Abbreviations \\ ANA: Anti-nuclear antibody; ANCA: Antineutrophil cytoplasmic antibodies; CH50: Complement 50; CT: Computed tomography; DLBCL: Diffuse large B cell lymphoma; EBV: Epstein-Barr virus; NHL: Non-Hodgkin lymphoma; PET-CT: Positron emission tomography-computed tomography.}

\section{Competing interests}

The authors declare that they have no competing interests.

\section{Authors' contributions}

CSK carried out the final preparation of the manuscript. YDC participated in the histological review of biopsies. JSC contributed in the discussion of the conclusions and performed the renal biopsy. EHB and SKM participated in the clinical follow-up of the patient. SWK contributed in the final preparation of the manuscript. All authors read and approved the final manuscript.

\section{Acknowledgements}

This research was supported by Basic Science Research Program through the National Research Foundation of Korea (NRF) funded by the Ministry of Education, Science and Technology (2011-0009743), and by the Korea Science and Engineering Foundation through the Medical Research Center for Gene Regulation grant (2012-0009448) at Chonnam National University.

\section{Author details}

'Department of Internal Medicine, Chonnam National University Medical School, 42 Jebongro, Gwangju 501-757, South Korea. ${ }^{2}$ Department of pathology, Chonnam National University Medical School, Gwangju, South Korea.

Received: 24 February 2012 Accepted: 8 November 2012

Published: 15 November 2012

\section{References}

1. Fox Rl, Howell FV, Bone RC, Michelson P: Primary Sjögren syndrome: clinical and immunopathologic features. Semin Arthritis Rheum 1984, 14:77-105.

2. Kaufman I, Schwartz D, Caspi D, Paran D: Sjögren's syndrome - not just Sicca: renal involvement in Sjögren's syndrome. Scand J Rheumatol 2008, 37:213-218.

3. Parambil JG, Myers JL, Lindell RM, Matteson EL, Ryu JH: Interstitial lung disease in primary Sjögren syndrome. Chest 2006, 130:1489-1495.

4. Ramos-Casals M, Anaya JM, Garcia-Carrasco M, Rosas J, Bove A, Claver G, Diaz LA, Herrero C, Font J: Cutaneous vasculitis in primary Sjögren syndrome: classification and clinical significance of 52 patients. Medicine (Baltimore) 2004, 83:96-106.

5. Mori K, lijima M, Koike H, Hattori N, Tanaka F, Watanabe H, Katsuno M, Fujita A, Aiba I, Ogata A, et al: The wide spectrum of clinical manifestations in Sjögren's syndrome-associated neuropathy. Brain 2005, 128:2518-2534.

6. Zintzaras E, Voulgarelis M, Moutsopoulos HM: The risk of lymphoma development in autoimmune diseases: a meta-analysis. Arch Intern Med 2005, 165:2337-2344.

7. Maripuri S, Grande JP, Osborn TG, Fervenza FC, Matteson EL, Donadio JV, Hogan MC: Renal involvement in primary Sjögren's syndrome: a clinicopathologic study. Clin J Am Soc Nephrol 2009, 4:1423-1431.

8. Daniels TE, Whitcher JP: Association of patterns of labial salivary gland inflammation with keratoconjunctivitis sicca. Analysis of 618 patients with suspected Sjögren's syndrome. Arthritis Rheum 1994, 37:869-877.

9. Schall GL, Anderson LG, Wolf RO, Herdt JR, Tarpley TM Jr, Cummings NA, Zeiger LS, Talal N: Xerostomia in Sjögren's syndrome. Evaluation by sequential salivary scintigraphy. JAMA 1971, 216:2109-2116.

10. Vitali C, Bombardieri S, Jonsson R, Moutsopoulos HM, Alexander EL, Carsons SE, Daniels TE, Fox PC, Fox RI, Kassan SS, et al: Classification criteria for Sjögren's syndrome: a revised version of the European criteria proposed by the American-European Consensus Group. Ann Rheum Dis 2002, 61:554-558.

11. Ponticelli C: Membranous nephropathy. J Nephrol 2007, 20:268-287.

12. Kassan SS, Thomas TL, Moutsopoulos HM, Hoover R, Kimberly RP, Budman DR, Costa J, Decker JL, Chused TM: Increased risk of lymphoma in sicca syndrome. Ann Intern Med 1978, 89:888-892.

13. Theander E, Henriksson G, Ljungberg O, Mandl T, Manthorpe R, Jacobsson LT: Lymphoma and other malignancies in primary Sjögren's syndrome: a cohort study on cancer incidence and lymphoma predictors. Ann Rheum Dis 2006, 65:796-803.

14. Sabattini E, Bacci F, Sagramoso C, Pileri SA: WHO classification of tumours of haematopoietic and lymphoid tissues in 2008: an overview. Pathologica 2010, 102:83-87.

15. Thorley-Lawson DA, Gross A: Persistence of the Epstein-Barr virus and the origins of associated lymphomas. N Engl J Med 2004, 350:1328-1337.

16. Park S, Lee J, Ko YH, Han A, Jun HJ, Lee SC, Hwang IG, Park YH, Ahn JS, Jung CW, et al: The impact of Epstein-Barr virus status on clinical outcome in diffuse large B-cell lymphoma. Blood 2007, 110:972-978.

17. Kassan SS, Moutsopoulos HM: Clinical manifestations and early diagnosis of Sjögren syndrome. Arch Intern Med 2004, 164:1275-1284.

18. Oyama T, Yamamoto K, Asano N, Oshiro A, Suzuki R, Kagami Y, Morishima Y, Takeuchi K, Izumo T, Mori S, et al: Age-related EBV-associated B-cell lymphoproliferative disorders constitute a distinct clinicopathologic group: a study of 96 patients. Clin Cancer Res 2007, 13:5124-5132.

19. Chuang SS, Ichinohasama R, Yang CC, Wang WC, Chou CK, Liao YL, Kuo SY, Lin SH: Multicentric primary intestinal EBV-positive diffuse large B cell lymphoma of the elderly presenting with perforation. Int J Hematol 2010, 91:534-538.

20. Pertovaara M, Korpela M, Kouri T, Pasternack A: The occurrence of renal involvement in primary Sjögren's syndrome: a study of 78 patients. Rheumatology (Oxford) 1999, 38:1113-1120. 
21. Yang J, Li X, Huang Q: [Renal involvement in primary Sjögren's syndrome: a clinicopathological study of 26 cases]. Zhonghua Nei Ke Za Zhi 1997, 36:28-31.

22. Goules A, Masouridi S, Tzioufas AG, loannidis JP, Skopouli FN, Moutsopoulos HM: Clinically significant and biopsy-documented renal involvement in primary Sjögren syndrome. Medicine (Baltimore) 2000, 79:241-249.

23. Bossini N, Savoldi S, Franceschini F, Mombelloni S, Baronio M, Cavazzana I, Viola BF, Valzorio B, Mazzucchelli C, Cattaneo R, et al: Clinical and morphological features of kidney involvement in primary Sjögren's syndrome. Nephrol Dial Transplant 2001, 16:2328-2336.

24. Siamopoulos KC, Mavridis AK, Elisaf M, Drosos AA, Moutsopoulos HM: Kidney involvement in primary Sjögren's syndrome. Scand I Rheumatol Suppl 1986, 61:156-160.

25. Moutsopoulos HM, Balow JE, Lawley TJ, Stahl NI, Antonovych TT, Chused TM: Immune complex glomerulonephritis in sicca syndrome. Am J Med 1978, 64:955-960.

26. Alpers CE, Cotran RS: Neoplasia and glomerular injury. Kidney Int 1986, 30:465-473

27. Moulin B, Ronco PM, Mougenot B, Francois A, Fillastre JP, Mignon F: Glomerulonephritis in chronic lymphocytic leukemia and related B-cell lymphomas. Kidney Int 1992, 42:127-135.

28. Seney FD Jr, Federgreen WR, Stein H, Kashgarian M: A review of nephrotic syndrome associated with chronic lymphocytic leukemia. Arch Intern Med 1986, 146:137-141

29. Touchard G, Preud'homme IL, Aucouturier P, Giraud C, Gouet D, Yver L, Patte D: Nephrotic syndrome associated with chronic lymphocytic leukemia: an immunological and pathological study. Clin Nephrol 1989, 31:107-116.

30. Eagen JW: Glomerulopathies of neoplasia. Kidney Int 1977, 11:297-303.

31. Ronco PM: Paraneoplastic glomerulopathies: new insights into an old entity. Kidney Int 1999, 56:355-377.

32. Herskowitz LJ, Gottlieb RP, Travis S: Nephrotic syndrome associated with non-Hodgkin's lymphoma: complete remission with chemotherapy. Clin Pediatr (Phila) 1982, 21:441-443.

33. Gagliano RG, Costanzi JJ, Beathard GA, Sarles HE, Bell JD: The nephrotic syndrome associated with neoplasia: an unusual paraneoplastic syndrome. Report of a case and review of the literature. Am J Med 1976 60:1026-1031

34. Banks RA, Kingswood JC, Slade R, Tribe CR, Harrison PR, Mackenzie JC: Glomerulonephritis, non-Hodgkin's lymphoma and leucocytoclastic vasculitis. Am J Nephrol 1984, 4:114-117.

35. Harper L, Adu D: Glomerulonephritis and non-Hodgkin lymphoma Nephrol Dial Transplant 1997, 12:1520-1525.

36. Imanaga N, Kamachi M, Fujikawa K, Aramaki T, Izumi Y, Arima K, Tamai M Aratake K, Nakamura H, Origuchi T, et al: Membraneous glomerulonephritis and non-Hodgkin's lymphoma in a patient with primary Sjögren's syndrome. Intern Med 2007, 46:191-194.

\section{Submit your next manuscript to BioMed Central and take full advantage of:}

- Convenient online submission

- Thorough peer review

- No space constraints or color figure charges

- Immediate publication on acceptance

- Inclusion in PubMed, CAS, Scopus and Google Scholar

- Research which is freely available for redistribution 